\title{
'All singing, all dancing': staff views on the integration of family planning and genitourinary medicine in Lothian, UK
}

\author{
Martin Higgins, ${ }^{1}$ Eric Zhong Chen, ${ }^{2}$ Ailsa E Gebbie, ${ }^{3}$ Imali Fernando, ${ }^{4}$ \\ Dona Milne, ${ }^{5}$ Rosemary Cochrane ${ }^{6}$
}

- Additional material is published online only. To view please visit the journal online (http://dx.doi.org/10.1136/jfprhc2013-100590)

For numbered affiliations see end of article.

\section{Correspondence to} Mr Martin Higgins, Public Health and Health Policy, NHS Lothian, Waverley Gate, 2-4 Waterloo Place, Edinburgh EH1 3EG, UK; martin.higgins@nhslothian.scot. nhs.uk

Received 14 January 2013 Revised 31 January 2014 Accepted 7 April 2014 Published Online First 20 May 2014

\section{CrossMark}

To cite: Higgins $\mathrm{M}$, Chen $\mathrm{EZ}$, Gebbie AE, et al. J Fam Plann Reprod Health Care 2014:40:254-260.

\begin{abstract}
Background UK policy documents advocate integrated approaches to sexual health service provision to ensure that everyone can access high-quality treatment. However, there is relatively little evidence to demonstrate any resultant benefits. The family planning and genitourinary medicine services in Lothian have been fully integrated and most care is now delivered from a purpose-built sexual health centre. We wished to study the views of staff on integrated sexual and reproductive care.

Methods Staff completed anonymous questionnaires before and after integration, looking at four main aspects: the patient pathway, specific patient groups, their own professional status, and their working environment. The surveys used a mixture of five-point Likert-type scales and open-ended questions.
\end{abstract}

Results Over $50 \%$ of staff completed the surveys on each occasion. Six months after the new building opened, staff attitudes about the integrated service were mixed. Staff reported more stress and less opportunity for specialisation but there was no change in their sense of professional status or development. There were concerns about how well the integrated service met the needs of specific patient groups, notably women. These concerns co-existed with a verdict that overall service quality was no worse following integration.

Conclusions Staff views should form an important part of service redesign and integration projects. Although the results from the Lothian surveys suggest a perceived worsening of some aspects of the service, further evaluation is needed to unpick the different problems that have appeared under the catch-all term of 'integration'.
Key messages

Evaluating staff experience of service redesign provides valuable insights for ongoing Quality Improvement.

- Preparation for an integrated service requires a focus on developing 'an integrated mindset' to overcome the challenges that a new working environment may create.

- Evidence on the specific processes and pathways that will deliver better outcomes from the integration of family planning and genitourinary medicine is currently lacking.

\section{INTRODUCTION}

Current UK policy documents advocate and recommend integrated approaches to sexual health service provision. ${ }^{1-3}$ An assumed benefit of integration is that it will lead to improved use of services and ensure that high-quality treatment can be accessed by all members of the population. ${ }^{4}$ The One-Stop Shop evaluation in England reported some evidence that a broader range of health care needs are addressed by clinicians working in integrated services compared to more specialist services. ${ }^{5}$ An earlier evaluation of the co-location of genitourinary medicine (GUM) and family planning (FP) and women's health services in Glasgow, UK concluded that the stigma associated with attending sexual health clinics was reduced; men continued to attend (GUM); patients' satisfaction with services increased; and referrals between 
specialties increased. ${ }^{6}$ Conversely, research in London, UK suggested that women attending for contraception only found the integrated sexual health clinic a more stigmatising experience than attending an FP-only clinic. $^{7}$

The One-Stop Shop evaluation also highlighted the importance of 'an integrated mindset' among staff. ${ }^{8}$ Elsewhere concerns have been expressed about the challenges that integration presents for staff who have devoted their professional lives to one specialty and find it hard to adapt to working with a new patient group outwith their comfort zone. A final theme relates to how well the service anticipates and meets patients' demands and needs. ${ }^{9}$ Work reporting on a redesigned sexual health service in London highlighted that organisational change, policy change and staff disagreements were just some of the factors that meant that any evaluation needed to be able to react to changes in the service it purported to measure. ${ }^{10} 11$

The Chalmers Centre in Edinburgh opened in 2011 as a purpose-built facility in which FP and GUM services have been centralised, serving 850000 people living in the Lothian region of Scotland. The two services have been completely integrated, with common treatment pathways for all patients accessing clinics. As part of a comprehensive integration project we wished to study the views of staff working within the service, before and after integration.

\section{METHODS}

A survey for staff was designed to gauge views of the service changes, based on a similar questionnaire used in the evaluation of the Glasgow service, which co-located their FP and GUM services in 2001. ${ }^{6}$ This could be completed online using SurveyMonkey ${ }^{\circledR}$ or in paper form. Participation in this study was voluntary and an information sheet was provided outlining the aims of the study.

The main research questions related to four aspects of staff views, namely: the patient pathway, specific patient groups, their own professional status, and their working environment. A pre-integration survey was conducted 9-12 months prior to integration. A post-integration survey was conducted 6-7 months after integration. Formal ethical approval was not sought for this study as the local National Health Service Research Ethics Committee advised that it was unnecessary. Staff were assured that responses would be treated in confidence and data presented anonymously. The sample comprised all staff working in the service at the time the surveys were conducted.

The surveys used a mixture of five-point Likert scales and open-ended questions. Questions were amended post-integration to ensure that the survey remained comprehensible but its meaning did not change. The data were repeat cross-sectional and Pearson's chi-square $\left(\chi^{2}\right)$ test (four degrees of freedom) was used to assess whether the changes in perception of staff were statistically different between the two time points. Due to the small numbers in some response cells, we have chosen to be cautious as regards the interpretation of change between each survey. Furthermore, we have collapsed the values into a three-point Likert scale to make Tables 2-5 easier to read. Please note that the $p$ values were calculated on the basis of the full five-point Likert scale and the original tables are available as online supplementary material. The significance levels of $p<0.01$ (denoted by **) and $p<0.05$ (denoted by *) were used in the analysis.

\section{RESULTS}

More than half the people employed in the service on each occasion completed the surveys and the proportions of different staff roles completing the survey were broadly similar in each wave (Table 1 ).

\section{Staff views about the patient pathway}

Table 2 shows that before integration staff were generally positive about the prospect of the integrated service improving patients' experience. After integration, staff were less enthusiastic about the service in the new centre and were less likely to recommend the service to others. On specific aspects of the service, scores significantly worsened between the two surveys in terms of access to appointments and registering on arrival as well as meeting the needs of patients.

Table 1 Demographic of respondents from pre-integration $(n=74)$ and post-integration ( $n=64)$ surveys

\begin{tabular}{|c|c|c|}
\hline Characteristics & $\begin{array}{l}\text { Pre-integration }[n \\
(\%) \text { of total staff)] }\end{array}$ & $\begin{array}{l}\text { Post-integration [n } \\
\text { (\%) of total staff)] }\end{array}$ \\
\hline Responses & $74(52)$ & $64(58)$ \\
\hline \multicolumn{3}{|l|}{ Role within service } \\
\hline Doctor & $26(35.1)$ & $24(37.5)$ \\
\hline $\begin{array}{l}\text { Nurses and health } \\
\text { advisers }\end{array}$ & $27(36.5)$ & $19(29.7)$ \\
\hline $\begin{array}{l}\text { Others: including } \\
\text { counsellors, support } \\
\text { workers, pharmacists }\end{array}$ & $6(8.1)$ & $7(10.9)$ \\
\hline $\begin{array}{l}\text { Administrative and } \\
\text { clerical }\end{array}$ & $15(20.2)$ & $14(21.8)$ \\
\hline \multicolumn{3}{|l|}{ Staff background } \\
\hline FP only & $33(44.6)$ & $29(45.3)$ \\
\hline GUM only & $24(32.4)$ & $15(23.4)$ \\
\hline Both services & $17(23.0)$ & $19(29.7)$ \\
\hline $\begin{array}{l}\text { Only in integrated } \\
\text { service }\end{array}$ & 0 & 1 (1.6) \\
\hline \multicolumn{3}{|l|}{ Age group (years) } \\
\hline$<30$ & $3(4.1)$ & $2(3.1)$ \\
\hline $30-39$ & $12(16.2)$ & $14(21.9)$ \\
\hline $40-49$ & $31(41.9)$ & $21(32.8)$ \\
\hline$\geq 50$ & $28(37.8)$ & $27(42.2)$ \\
\hline
\end{tabular}

FP, family planning; GUM, genitourinary medicine. 
Article

Table 2 Staff views on how the integrated service affects the patient experience

\begin{tabular}{|c|c|c|c|c|c|}
\hline Aspects of the patient pathway & Survey $(n)$ & A little or a lot worse (\%) & The same $(\%)$ & A little or a lot better (\%) & $p+$ \\
\hline \multirow[t]{2}{*}{ Ease of making an appointment } & Pre (72) & 10 & 33 & 57 & $<0.01^{* *}$ \\
\hline & Post (61) & 93 & 7 & 0 & \\
\hline \multirow[t]{2}{*}{ Availability of appointments } & Pre (72) & 19 & 32 & 49 & $<0.01 * *$ \\
\hline & Post (61) & 90 & 8 & 2 & \\
\hline \multirow[t]{2}{*}{ Getting to the clinic } & Pre (74) & 9 & 61 & 30 & 0.38 \\
\hline & Post (62) & 5 & 71 & 24 & \\
\hline \multirow[t]{2}{*}{ Disability access } & Pre (73) & 0 & 15 & 85 & $0.04^{*}$ \\
\hline & Post (63) & 2 & 8 & 90 & \\
\hline \multirow[t]{2}{*}{ Getting registered at reception } & Pre (72) & 8 & 46 & 46 & $<0.01$ ** \\
\hline & Post (56) & 36 & 39 & 25 & \\
\hline \multirow[t]{2}{*}{ Waiting time to be seen by clinician } & Pre (72) & 17 & 57 & 26 & 0.18 \\
\hline & Post (59) & 34 & 54 & 12 & \\
\hline \multirow[t]{2}{*}{ Quality of care received } & Pre (73) & 22 & 47 & 32 & 0.06 \\
\hline & Post (63) & 16 & 46 & 38 & \\
\hline \multirow[t]{2}{*}{ Meeting the needs of patients } & Pre (73) & 11 & 34 & 55 & $<0.01^{* *}$ \\
\hline & Post (63) & 40 & 17 & 43 & \\
\hline \multirow[t]{2}{*}{ Opportunity for health promotion/screening } & Pre (72) & 14 & 25 & 61 & 0.18 \\
\hline & Post (60) & 13 & 43 & 43 & \\
\hline \multirow[t]{2}{*}{ Overall time spent in clinic } & Pre $(72)$ & 24 & 42 & 35 & 0.06 \\
\hline & Post (60) & 43 & 42 & 15 & \\
\hline \multirow[t]{2}{*}{ Overall satisfaction } & Pre (72) & 15 & 36 & 49 & $<0.01 * *$ \\
\hline & Post (59) & 49 & 31 & 20 & \\
\hline
\end{tabular}

Significance levels: ${ }^{*} p<0.05,{ }^{*} p<0.01$

†Note: $p$ values were calculated on the basis of a five-point Likert scale; the original table is available online (Supplementary Table 2).

Table 3 Staff views on how the integrated service catered to the different patient groups

\begin{tabular}{|c|c|c|c|c|c|}
\hline Patient groups & Survey $(n)$ & A little or a lot worse (\%) & The same $(\%)$ & A little or a lot better (\%) & $p \dagger$ \\
\hline \multirow[t]{2}{*}{ Heterosexual men } & Pre (72) & 7 & 51 & 42 & 0.28 \\
\hline & Post (58) & 12 & 62 & 26 & \\
\hline \multirow[t]{2}{*}{ Heterosexual women } & Pre (72) & 13 & 32 & 56 & $<0.01^{* *}$ \\
\hline & Post (61) & 51 & 31 & 18 & \\
\hline \multirow[t]{2}{*}{ Gay and bisexual men } & Pre (71) & 8 & 63 & 28 & 0.51 \\
\hline & Post (58) & 12 & 71 & 17 & \\
\hline \multirow[t]{2}{*}{ Lesbian and bisexual women } & Pre (72) & 1 & 64 & 35 & 0.07 \\
\hline & Post (56) & 11 & 71 & 18 & \\
\hline \multirow[t]{2}{*}{ Transgendered individuals } & Pre (71) & 4 & 68 & 28 & $0.03^{*}$ \\
\hline & Post (56) & 5 & 86 & 9 & \\
\hline \multirow[t]{2}{*}{ Young people } & Pre (73) & 7 & 30 & 63 & $<0.01^{* *}$ \\
\hline & Post (59) & 37 & 25 & 37 & \\
\hline \multirow[t]{2}{*}{ Older women } & Pre (73) & 34 & 34 & 32 & $<0.01^{* *}$ \\
\hline & Post (61) & 66 & 23 & 11 & \\
\hline \multirow[t]{2}{*}{ HIV-positive individuals } & Pre (73) & 3 & 71 & 26 & 0.58 \\
\hline & Post (58) & 5 & 78 & 17 & \\
\hline \multirow[t]{2}{*}{ Sex workers and drug users } & Pre (73) & 4 & 53 & 42 & $<0.01^{* *}$ \\
\hline & Post (58) & 9 & 79 & 12 & \\
\hline \multirow[t]{2}{*}{ Ethnic minorities } & Pre (73) & 7 & 71 & 22 & $0.02^{*}$ \\
\hline & Post (58) & 10 & 88 & 2 & \\
\hline \multirow[t]{2}{*}{ Those referred from other organisations } & Pre (73) & 4 & 63 & 33 & $<0.01^{* *}$ \\
\hline & Post (60) & 18 & 77 & 5 & \\
\hline
\end{tabular}

Significance levels: ${ }^{*} p<0.05,{ }^{* *} p<0.01$.

tNote: $p$ values were calculated on the basis of a five-point Likert scale; the original table is available online (Supplementary Table 3). 
Table 4 Staff views on how the integrated service caters to the needs of individuals who attended for specific reasons

\begin{tabular}{|c|c|c|c|c|c|}
\hline Patient groups & Survey $(n)$ & A little or a lot worse (\%) & The same (\%) & A little or a lot better (\%) & $p+$ \\
\hline \multirow[t]{2}{*}{ Infertility problems } & Pre (72) & 14 & 58 & 28 & $<0.01^{* *}$ \\
\hline & Post (57) & 35 & 63 & 2 & \\
\hline \multirow[t]{2}{*}{ (Psycho)sexual problems } & Pre (71) & 7 & 73 & 20 & $0.03^{*}$ \\
\hline & Post (57) & 14 & 84 & 2 & \\
\hline \multirow[t]{2}{*}{ Genital skin problems } & Pre (72) & 4 & 56 & 40 & 0.09 \\
\hline & Post (57) & 14 & 56 & 30 & \\
\hline \multirow[t]{2}{*}{ Gynaecology problems } & Pre (71) & 7 & 63 & 30 & 0.08 \\
\hline & Post (59) & 20 & 61 & 19 & \\
\hline \multirow[t]{2}{*}{ Abortion care } & Pre (72) & 4 & 60 & 36 & $<0.01$ ** \\
\hline & Post (59) & 20 & 68 & 12 & \\
\hline \multirow[t]{2}{*}{ Contraception } & Pre (71) & 14 & 49 & 37 & $<0.01$ ** \\
\hline & Post (62) & 65 & 23 & 13 & \\
\hline \multirow[t]{2}{*}{ Smears } & Pre (73) & 7 & 55 & 38 & $<0.01^{* *}$ \\
\hline & Post (61) & 49 & 38 & 13 & \\
\hline \multirow[t]{2}{*}{ Colposcopy treatment } & Pre (71) & 0 & 66 & 34 & $<0.01$ ** \\
\hline & Post (58) & 7 & 84 & 9 & \\
\hline \multirow[t]{2}{*}{ Menopause problems } & Pre (72) & 11 & 64 & 25 & $0.04^{*}$ \\
\hline & Post (59) & 20 & 73 & 7 & \\
\hline \multirow[t]{2}{*}{ STI testing and treatment } & Pre (72) & 0 & 49 & 51 & $<0.01^{* *}$ \\
\hline & Post (59) & 15 & 51 & 34 & \\
\hline \multirow[t]{2}{*}{ Adolescent gynaecology problems } & Pre (71) & 7 & 69 & 24 & $0.02^{*}$ \\
\hline & Post (56) & 16 & 79 & 5 & \\
\hline \multirow[t]{2}{*}{ Sexual assault counselling } & Pre $(70)$ & 3 & 63 & 34 & $<0.01$ ** \\
\hline & Post (56) & 11 & 80 & 9 & \\
\hline
\end{tabular}

Significance levels: ${ }^{*} p<0.05,{ }^{*} p<0.01$.

†Note: $p$ values were calculated on the basis of a five-point Likert scale; the original table is available online (Supplementary Table 4).

STI, sexually transmitted infection.

\section{Different patient groups}

Table 3 shows that staff expressed concern that the needs of patients might not be met by the integrated service. Although the absolute numbers were small, post-integration responses indicated that staff felt that many patient groups were not being well served, particularly heterosexual women, older women and young people. Staff group analysis showed that doctors were the least positive about the changes.

\section{Reasons for attendance}

Table 4 shows that before integration there was a degree of concern about patient groups who attended for contraception, smears, menopause and infertility. Post-integration there was a significant change in staff views about how well the service catered to specific clinical needs. There was increased concern that patients attending specialist clinics for infertility problems, psychosexual problems, abortion care, contraception, smears, colposcopy, menopause, sexually transmitted infections, adolescent gynaecology and sexual assault counselling were not receiving optimal services.

\section{Professional development and work environment}

In the pre-integration survey staff were clear that they expected integration to improve the service, their own clinical practice and their work environment (Table 5). There was less enthusiasm in the postintegration survey about the extent to which the service has actually improved. All six Likert items offering positive statements about potential postintegration services show a significant decline in levels of optimism and enthusiasm. There was also a reduction in the number of staff who agreed that the service provided a more conducive work environment. There was, however, no change in the responses about professional status and career development, which scored well in both surveys.

\section{Comments}

After each set of questions, staff were invited to add comments, allowing an opportunity to raise issues that the closed questions did not address. ${ }^{12}$ The responses provided insights into the perspectives of staff and in some cases the strength of feeling about an issue, which could be related to the quantitative analysis. A small selection of illustrative comments are included here. 
Table 5 Staff views on how the integrated service affects their professional development and work environment

\begin{tabular}{|c|c|c|c|c|c|}
\hline Statements & $\begin{array}{l}\text { Survey } \\
(n)\end{array}$ & $\begin{array}{l}\text { Strongly agree } \\
\text { or agree }(\%)\end{array}$ & $\begin{array}{l}\text { Neutral } \\
(\%)\end{array}$ & $\begin{array}{l}\text { Strongly disagree } \\
\text { or disagree }(\%)\end{array}$ & $p \dagger$ \\
\hline \multicolumn{6}{|l|}{ Positive statements } \\
\hline \multirow[t]{2}{*}{ Providing opportunities for learning new skills } & Pre (72) & 93 & 1 & 6 & $<0.01^{* *}$ \\
\hline & Post (62) & 71 & 18 & 11 & \\
\hline \multirow[t]{2}{*}{ Adding variety into the work } & Pre (74) & 86 & 7 & 7 & $0.03^{*}$ \\
\hline & Post (62) & 68 & 23 & 10 & \\
\hline \multirow[t]{2}{*}{ Improving the quality of patient care } & Pre (73) & 55 & 29 & 16 & $<0.01^{* *}$ \\
\hline & Post (62) & 29 & 40 & 31 & \\
\hline \multirow[t]{2}{*}{ Providing a positive and conducive work environment } & Pre (74) & 58 & 34 & 8 & $0.02^{*}$ \\
\hline & Post (62) & 34 & 39 & 27 & \\
\hline \multirow[t]{2}{*}{ Is more cost effective compared to having separate services } & Pre (74) & 61 & 31 & 8 & $0.03^{*}$ \\
\hline & Post (59) & 34 & 54 & 12 & \\
\hline \multirow[t]{2}{*}{ Is a good example of what all FP and GUM services should aspire to } & Pre (74) & 68 & 26 & 7 & $0.02^{*}$ \\
\hline & Post (59) & 49 & 24 & 27 & \\
\hline \multicolumn{6}{|l|}{ Negative statements } \\
\hline \multirow[t]{2}{*}{ Negatively affecting professional status } & Pre (73) & 7 & 34 & 59 & 0.19 \\
\hline & Post (62) & 15 & 42 & 44 & \\
\hline \multirow[t]{2}{*}{ Negatively affecting career development } & Pre (74) & 5 & 30 & 65 & 0.13 \\
\hline & Post (62) & 11 & 42 & 47 & \\
\hline \multirow[t]{2}{*}{ Problematic given the contradictory culture between the two services } & Pre (72) & 33 & 28 & 39 & 0.35 \\
\hline & Post (61) & 44 & 28 & 28 & \\
\hline \multirow[t]{2}{*}{ Resulting in the loss of some of (specialist) skills } & Pre (73) & 12 & 23 & 64 & $0.02^{*}$ \\
\hline & Post (61) & 33 & 21 & 46 & \\
\hline \multirow[t]{2}{*}{ Being a challenge due to inadequate training provided } & Pre (74) & 32 & 34 & 34 & 0.08 \\
\hline & Post (61) & 48 & 33 & 20 & \\
\hline \multirow[t]{2}{*}{ Being more stressful than before } & Pre (74) & 55 & 24 & 20 & $<0.01$ ** \\
\hline & Post (62) & 73 & 15 & 13 & \\
\hline
\end{tabular}

Significance levels: * $p<0.05,{ }^{* *} p<0.01$.

†Note: $p$ values were calculated on the basis of a five-point Likert scale; the original table is available online (Supplementary Table 5).

$\mathrm{FP}$, family planning; GUM, genitourinary medicine.

Before integration

"I believe that in making it an 'all singing, all dancing' service, we dilute experience and thus there is potential for service to be worse, lower patient level of care."

[GU15 doctor]

"As there is a broader range of issues to cover in sexual health history taking, I am worried that time limits will reduce the ability to do preventative and health promotion activities." [SM10 nurse]

"Overall, I think the patients will have more on offer and a comprehensive service but possibly at the expense of providing a very individual service."

[SM12 doctor]

'I feel that patients' needs may be ignored if they do not fall into certain groups, the average middle-aged woman who is just coming in for a smear and a quick contraceptive chat may be put off by the different type of clientele who attend the new sexual health service." [FP3 administrative]
After integration

"I feel we have taken two centres of excellence and turned [them] into one average centre. Many of the staff feel more stressed now than when we first integrated. The patients from each specialty have very different needs and expectations from the service and I feel we have disfranchised a fair number of our patients.” [P15 nurse]

"Apart from issues with patients complaining about the appointments, I think, having worked in both GUM and family planning prior to the integration, Chalmers offers a better clinical service and there are definite advantages to having both services together, especially for doing smears or for areas such as termination or sexual assault." [SM25 doctor]

"The most stressful 6 months since starting in sexual health. I do not attribute any of the problems to integration per se. They are due largely to staff levels, capacity issues and NaSH." [P32 doctor]

[NB. NaSH is Scotland's National Sexual Health electronic patient record, which was designed to support integrated FP and GUM services.] 
"Lots of complaints from patients. Time of waiting on phones, lack of appointments to give to patients."

[P1 administrative]

\section{DISCUSSION}

The results overall suggested that staff were significantly less enthusiastic about the integrated service 6 months after it had opened compared to 9 months before opening. Views on service quality for different patient groups and for particular clinical services had in general worsened. There was support for the proposition that the physical environment of the new centre was better, and while staff worried about a perceived loss of expertise, there was little evidence to suggest that they felt their professional status was threatened.

There have been problems for patients accessing the new appointments system since the centre opened, which reached the pages of the local press. ${ }^{13}$ The balance of booked appointments and walk-in has been the subject of ongoing quality improvement and this aspect of the service is constantly under review. It is entirely possible that the timing of the follow-up staff survey influenced responses. Many of the administrative and computer problems were at their worst in the first 8 months after integration.

Previous research into integration has highlighted the tensions that may exist between the converging specialties. ${ }^{14}$ The surveys suggested that staff were generally positive about the integration beforehand and more ambivalent after integration. Staff reported more stress and less opportunity for specialisation, which might be expected in an integrated service. Notably, the One-Stop Shop evaluation recommendation about an 'integrated mindset' does not yet appear to be met. The research literature about integration emphasises the importance of preparatory staff training and development. This happened in Edinburgh, yet problems have arisen.

The logic for integration between FP and GUM is well rehearsed even if the benefits have proven difficult to capture. The physical relocation of services cannot be easily reversed and there seemed to be consensus about positive aspects of the working environment. The research literature is equivocal about whether 'full' integration is the optimal arrangement for FP and GUM. So it cannot be assumed that satisfaction with the physical environment will eventually translate into contentment with working practices.

\section{CONCLUSIONS}

Staff views should form an important part of service redesign and integration projects. Within the new Lothian integrated sexual and reproductive health service these surveys of staff views have informed practice and formed a significant element of the service's quality improvement programme. Although the results suggest a perceived worsening of various aspects of the service following integration, further evaluation should be undertaken to unpick the different problems that have appeared under the catch-all term of 'integration', which should offer fruitful options for ongoing service improvement.

\section{Study limitations}

The surveys are cross-sectional rather than cohort studies and we were unable to link responses in our two survey waves at an individual level. More than $50 \%$ of staff responded on both occasions but it is possible that our results are characterised by response bias. The open-ended questions offer some insights into staff thinking but ought not to be viewed as in-depth qualitative research.

\section{Author affiliations}

${ }^{1}$ Senior Public Health Researcher, Public Health and Health Policy, NHS Lothian, Edinburgh, UK

${ }^{2} \mathrm{PhD}$ Student, School of Social and Political Science, University of Edinburgh, Edinburgh, UK

${ }^{3}$ Consultant Gynaecologist, NHS Lothian Sexual and Reproductive Health Service, Chalmers Centre, Edinburgh, UK

${ }^{4}$ Consultant Physician, NHS Lothian Sexual and

Reproductive Health Service, Chalmers Centre, Edinburgh, UK

${ }^{5}$ Public Health Specialist, Public Health and Health

Policy, NHS Lothian, Edinburgh, UK

${ }^{6}$ Specialty Trainee, NHS Lothian Sexual and Reproductive Health Service, Chalmers Centre, Edinburgh, UK

\section{Competing interests None.}

Ethics approval Not required.

Provenance and peer review Not commissioned; externally peer reviewed.

\section{REFERENCES}

1 Scottish Government. The Sexual Health and Blood Borne Virus Framework 2011-15. Edinburgh, UK: Scottish Government, 2011.

2 Scottish Executive. Respect and Responsibility: Strategy and Action Plan for Improving Sexual Health. Edinburgh, UK: Scottish Government, 2005.

3 Department of Health. Better Prevention, Better Services, Better Sexual Health: The National Strategy for Sexual Health and HIV. London, UK: HMSO, 2001.

4 Wilkinson C, Hampton N, Bradbeer C. The integration of family planning and genitourinary medicine services. Br J Fam Plann 2000;26:187-189.

5 French RS, Mercer CH, Robinson AJ, et al. Addressing sexual health needs: a comparison of a one-stop shop with separate genitourinary medicine and family planning services. J Fam Plann Reprod Health Care 2010;36:202-209.

6 Kinn S, MacDonald C, Hinks S, et al. Client and staff views on facilities and services, before and after the convergence of sexual, reproductive and women's services. Eur J Contracept Reprod Health Care 2003;8:65-74. 
7 Sauer U, Singh A, Rubenstein P, et al. Do women requesting only contraception find attendance at an integrated sexual health clinic more stigmatizing than attendance at a family planning-only clinic? Int $J$ Womens Health 2013;5:57-64.

8 One-Stop Shop Evaluation Team. Evaluation of One-Stop Shop Models of Sexual Health Provision: Executive Summary. London, UK: Department of Health, 2007.

9 Hitchings S, Allotey J, Pittrof R. Do sexual health staff know what patients want from services? Int J STD AIDS 2010;21:202-204.

10 Greenhalgh T, Macfarlane F, Barton-Sweeney C, et al. "If we build it, will it stay?" A case study of the sustainability of whole-system change in London. Milbank Q 2012;90: 516-547.

11 Greenhalgh T, Humphrey C, Hughes J, et al. How do you modernize a health service? A realist evaluation of whole-scale transformation in London. Milbank Q 2009;87:391-416.

12 O'Cathain A, Thomas K. "Any other comments?” Open questions on questionnaires - a bane or a bonus to research? BMC Med Res Methodol 2011;4:25.

13 Morris A. Phone fault hits sexual health clinic. Edinburgh Evening News, 26 September 2011.

14 Kane R, Wellings K. Integrated sexual health services: the views of medical professionals. Cult Health Sex 1999;1:131-145. 